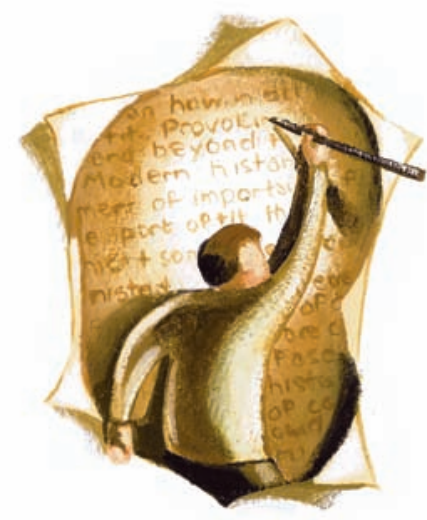

REAP: an extended agenda

\section{for the clinical interview}

The value of skillful communication in reaching the correct diagnosis, providing high-quality medical care and nurturing the patient-physician relationship cannot be overestimated. ${ }^{1}$ Communication starts with the medical interview. Physicians (and medical students) usually conduct these interviews according to the traditional structure of chief complaint, present illness, past medical history, review of systems and so on. However, both in the teaching of medical interviewing techniques and in practice, more emphasis is needed on the pursuit of several additional goals, which can be easily remembered by the mnemonic REAP: $\mathrm{R}$ for the "regular" components of the interview, E for both "emotion" and "education," A for "alarms" and P for "prevention" and "preferences."

Being sensitive to the patient's narrative and to nonbiologic components of the illness is increasingly recognized as crucially important. ${ }^{2,3}$ Because health literacy and patient awareness are the sine qua non of improved health outcomes and shared decision-making, education that begins at this early point would undoubtedly add to the patient's autonomy and satisfaction. ${ }^{4}$ Potential "alarms" identified in the initial presentation require urgent attention, and delay in their recognition might prove dangerous to the patient. An inquiry about the current status of preventive care is mandatory to draw attention to deficiencies that often can be easily cor- rected. Finally, obtaining at least a rough idea about the patient's preferences $^{5}$ reminds us that patients are different and that their differences ought to be respected.

Thus, REAP is a useful reminder of several essential aspects of the medical interview. Including these points will ensure that we harvest improved patient care.

\section{Ami Schattner}

Hebrew University Hadassah Medical School

Jerusalem, Israel

\section{REFERENCES}

I. Maguire P, Pitceathly C. Key communication skills and how to acquire them. BMJ 2002;325:697-700.

2. Schattner A. The emotional dimension and the biological paradigm of illness: time for a change. QJM 2003;96:6I7-2I.

3. Haidet P, Paterniti DA. "Building" a history rather than "taking" one. A perspective on information sharing during the medical interview. Arch Intern Med 2003;I63:II34-40.

4. Heisler M, Bouknight RR, Hayward RA, et al. The relative importance of physician communication, participatory decision making, and patient understanding in diabetes self-management. J Gen Intern Med 2002; 17:243-52.

5. Schattner A, Tal M. Truth telling and patient autonomy: the patient's point of view. Am J Med 2002;II3:66-9.

DOI:I0.1503/cmaj.1060138

\section{An economical cure}

I am a retired physician whose left big toenail became heavily colonized by an unidentified fungus with resultant thickening, opacity and deformation. A respected dermatologist confirmed my diagnosis, but we decided not to initiate any treatment. The cost of oral treatments ranges from about $\$ 250$ to $\$ 500$, and there are many serious side effects. ${ }^{1-3}$

Shortly after the consultation, I decided to undertake a trial of topical iodine. I obtained a bottle of $2.5 \%$ iodine tincture at a cost of $\$ 3.27$, and applied one drop of the solution daily, with occasional lapses, to the tip of the affected toenail. The iodine travelled rap- idly into the depths of the affected subungual tissues.

After 2 weeks, a sliver of normallooking nail appeared at the proximal end of the affected nail. Encouraged, I continued the treatment. The nail grew at the normal slow rate, and the diseased area gradually moved distally. The nail is now apparently normal.

The total cost of the treatment was $\$ 3.27$, and half of the original bottle of iodine solution remains for further treatment, if required. In view of the efficacy of the treatment in this isolated case, it would seem reasonable to institute a trial with a larger number of patients to obtain scientifically acceptable results. However, blinded trials would be difficult, given the telltale colour and odour of iodine. No side effects were observed in the case described.

\section{Russell Davidson \\ Victoria, BC}

\section{REFERENCES}

I. Ketoconazole, oral antifungal. In: Compendium of pharmaceuticals and specialties. Ottawa: Canadian Pharmacists Assocation; 2005. p. I07I-3.

2. Rodgers P, Bassler M. Treating onychomycosis. Am Fam Physician 2001;63:663-72, 677-8.

3. Elewski BE. Onychomycosis. Treatment, quality of life, and economic issues. Am J Clin Dermatol 2000;I(I):19-26.

DOI:I0.1503/cmaj.1060156

\section{Health benefits of physical}

\section{activity}

Darren Warburton and colleagues ${ }^{1}$ have done a thorough job of presenting the evidence for the health benefits of physical exercise, but a cautionary note may be in order.

Every book on exercise that I have seen carries the caveat that the reader should check with a physician before starting a fitness program. Yet a person's family doctor may lack the necessary qualifications to assess the potential risks. Physicians and anyone else 
involved in another person's fitness efforts must be aware of their responsibility to temper newfound enthusiasm for fitness and health with common sense.

\section{Herbert H. Nehrlich \\ Private practice \\ Bribie Island, Australia}

\section{REFERENCE}

I. Warburton DER, Nicol CW, Bredin SSD. Health benefits of physical activity: the evidence. CMAJ 2006;174(6):80I-9.

DOI:I0.1503/cmaj.1060095

Darren Warburton and colleagues ${ }^{1}$ conclude that "there appears to be a linear relation between physical activity and health status, such that a further increase in physical activity and fitness will lead to additional improvements in health status." Although Health Canada's guidelines on physical activity appear sufficient to elicit health benefits, especially in previously sedentary people, debate continues regarding the intensity and type of physical activity needed to achieve the most favourable health changes without eliciting osteoarthritis and cardiovascular abnormalities not present at rest. ${ }^{2}$ The results of our own recent investigations of toplevel endurance athletes ${ }^{3-5}$ support the conclusion that substantial intensification of leisure-time physical activity does not increase the risk of adverse cardiovascular events and is likely to be effective in eliciting supplemental health gains. We further suggest that higher intensities and amounts of aerobic training may be safely implemented by sedentary individuals living in the community as a measure to gain further health advantages, especially for those most at risk of cardiovascular problems, osteoporosis and cancer. ${ }^{1}$

\section{Giuseppe Lippi \\ Federico Schena}

\section{Gian Cesare Guidi}

Istituto di Chimica e Microscopia

Clinica

Dipartimento di Scienze,

Morfologico-Biomediche

Università degli Studi di Verona

Verona, Italy

\section{REFERENCES}

I. Warburton DER, Nicol CW, Bredin SSD. Health benefits of physical activity: the evidence. $C M A J$ 2006;174(6):80I-9.

2. Lee IM, Sesso HD, Oguma Y, et al. Relative intensity of physical activity and risk of coronary heart disease. Circulation 2003;107:1110-6.

3. Lippi G, Salvagno GL, Montagana M, et al. Chronic influence of vigorous aerobic training on hemostasis. Blood Coagul Fibrinolysis 2005; 16:533-4.

4. Lippi G, Salvagno GL, Guidi GC. Other advantages to aerobic exercise [letter]. CMAJ 2005;I73:I066.

5. Lippi G, Salvagno GL, Montagnana M, et al. Influence of physical exercise and relationship with biochemical variables of NT-pro-brain natriuretic peptide and ischemia modified albumin. Clin Chim Acta 2005;367(I-2):175-80.

DOI:I0.1503/cmaj.1060094

As described by Darren Warburton and colleagues, ${ }^{1}$ regular physical activity provides a variety of health and fitness benefits. However, barriers to exercise are frequently reported, including lack of time, lack of access and lack of safe environments in which to work out. ${ }^{2}$ Increased availability of affordable, secure environments for physical activities combined with acceptable exercise choices, such as walking, swimming, biking or fitness classes, may increase activity levels.

However, education alone does not motivate changes in behaviour, nor will such changes be made before a person is ready to do so. ${ }^{3}$ Researchers and health care providers have implemented health-promoting interventions for diverse groups of people for many years with mixed success. ${ }^{4}$ They have also reported that disease and disability disproportionately affect racial and ethnic minorities and impoverished people. ${ }^{5}$ Therefore, we need to develop and deliver inclusive, culturally appropriate interventions to increase and encourage active lifestyles and healthy diets in our communities.

Highlighting the public health benefits of physical activities and active lifestyles, as Warburton and colleagues ${ }^{1}$ have done, is important. Discussing barriers to physical activities and suggesting solutions, as well as making recommendations about best practices to increase physical activities, are just as important. To slow and reverse current trends in obesityrelated health problems, highly effective health promotion interventions and removal of barriers to active lifestyles and healthy diets are greatly needed. ${ }^{6}$

\section{Ediriweera Desapriya \\ Ian Pike \\ Shelina Babul}

Department of Pediatrics

Centre for Community Child Health

Research

Vancouver, BC

\section{REFERENCES}

I. Warburton DER, Nicol CW, Bredin SSD. Health benefits of physical activity: the evidence. CMAJ 2006;174(6):80I-9.

2. French SA, Story M, Jeffery RW. Environmental influences on eating and physical activity. Annu Rev Public Health 2001;22;309-35.

3. Sneed NV, Paul SC. Readiness for behavioral changes in patients with heart failure. Am J Crit Care 2003;I2(5):444-53

4. Wanko NS, Brazier CW, Young-Rogers D, et al. Exercise preferences and barriers in urban African Americans with type 2 diabetes. Diabetes Educ 2004;30(3):502-I3.

5. Brownson RC, Eyler AA, King AC. Reliability of information on physical activity and other chronic disease risk factors among US women aged 40 years or older. Am J Epidemiol I999;I49:379-9I.

6. Desapriya E. Obesity epidemic [letter]. Lancet 2004;364:1488.

DOI:I0.I503/cmaj.Io60093

For a substantial proportion of the population in impoverished nations, physical activity is more or less essential to earning a livelihood, rather than being just another activity aimed toward better health. To make ends meet, a subsistence farmer or manual labourer must start early in the morning and work until late in the evening. For example, the tricycle rickshaw is still a means of transport in some places, and the pedaller burns an immense number of calories throughout the day. But at the end of the day, his health may not have improved, despite his supposedly deriving health benefits from aerobic physical activity. ${ }^{1-3}$ Therefore, it seems that more than physical activity alone is needed.

Instead, various factors probably interact with physical activity to generate the health benefits observed. Although the study by Darren Warburton and associates $^{1}$ is meticulous, detailed and interesting, the interplay of an adequate balanced diet, timely replenishment of essential minerals and nutrients, the environment, adequate rest, psycho- 